\title{
Intensive insulin therapy and mortality among critically ill patients: a meta-analysis including NICE-SUGAR study data
}

\author{
Donald E.G. Griesdale MD MPH, Russell J. de Souza RD MSc, Rob M. van Dam PhD, \\ Daren K. Heyland MD, Deborah J. Cook MD MSc, Atul Malhotra MD, Rupinder Dhaliwal RD, \\ William R. Henderson MD, Dean R. Chittock MD MS(Epi), Simon Finfer MBBS, Daniel Talmor MD MPH
}

Published at www.cmaj.ca on Mar. 24, 2008.

$\infty \infty$

See related commentary by Van den Berghe and colleagues, page 799

\section{ABSTRACT}

Background: Hyperglycemia is associated with increased mortality in critically ill patients. Randomized trials of intensive insulin therapy have reported inconsistent effects on mortality and increased rates of severe hypoglycemia. We conducted a meta-analysis to update the totality of evidence regarding the influence of intensive insulin therapy compared with conventional insulin therapy on mortality and severe hypoglycemia in the intensive care unit (ICU).

Methods: We conducted searches of electronic databases, abstracts from scientific conferences and bibliographies of relevant articles. We included published randomized controlled trials conducted in the ICU that directly compared intensive insulin therapy with conventional glucose management and that documented mortality. We included in our meta-analysis the data from the recent NICE-SUGAR (Normoglycemia in Intensive Care Evaluation - Survival Using Glucose Algorithm Regulation) study.

Results: We included 26 trials involving a total of 13567 patients in our meta-analysis. Among the 26 trials that reported mortality, the pooled relative risk (RR) of death with intensive insulin therapy compared with conventional therapy was 0.93 (95\% confidence interval $[\mathrm{Cl}]$ 0.83-1.04). Among the 14 trials that reported hypoglycemia, the pooled RR with intensive insulin therapy was $6.0(95 \% \mathrm{Cl}$ 4.5-8.0). The ICU setting was a contributing factor, with patients in surgical ICUs appearing to benefit from intensive insulin therapy (RR $0.63,95 \% \mathrm{Cl} 0.44-0.91)$; patients in the other ICU settings did not (medical ICU: RR 1.0, 95\% CI 0.78-1.28; mixed ICU: RR 0.99, 95\% Cl 0.86-1.12). The different targets of intensive insulin therapy (glucose level $\leq 6.1 \mathrm{mmol} / \mathrm{L}$ v. $\leq 8.3 \mathrm{mmol} / \mathrm{L}$ ) did not influence either mortality or risk of hypoglycemia.

Interpretation: Intensive insulin therapy significantly increased the risk of hypoglycemia and conferred no overall mortality benefit among critically ill patients. However, this therapy may be beneficial to patients admitted to a surgical ICU.

Une version française de ce résumé est disponible à l'adresse www.cmaj.ca/cgi/content/full/180/8/821/DC1

CMAJ 2009;180(8):821-7
$\mathrm{H}$ yperglycemia is associated with adverse outcomes, including increased mortality, in acutely ill patients..$^{1-7}$ In 2001, a randomized trial involving patients admitted to a surgical intensive care unit (ICU) showed that intensive insulin therapy, targeting a blood glucose concentration of 4.4-6.1 $\mathrm{mmol} / \mathrm{L}$, significantly reduced in-hospital mortality. ${ }^{8}$ Subsequent trials have failed to confirm a mortality benefit with intensive insulin therapy among critically ill patients, in whom stress hyperglycemia is common. ${ }^{9-13} \mathrm{~A}$ recent meta-analysis concluded that such therapy did not reduce mortality among critically ill patients. ${ }^{14}$ Despite conflicting evidence, intensive insulin therapy has been recommended as the standard of care for critically ill patients by the American Diabetes Association, ${ }^{15}$ the American Association of Clinical Endocrinologists ${ }^{16}$ and other professional organizations. ${ }^{17} \mathrm{~A}$ consistent finding in trials of such therapy has been an increased risk of severe hypoglycemia, which was the impetus for early termination of 2 large European trials..$^{11,13}$ The Normoglycemia in Intensive Care Evaluation Survival Using Glucose Algorithm Regulation (NICE-SUGAR) study, an international multicentre trial involving 6104 patients, is the largest trial of intensive insulin therapy to date..$^{18}$ It has reported 1580 deaths. In light of the recently published NICESUGAR data, we conducted a systematic review and metaanalysis of randomized trials of intensive insulin therapy in critically ill patients to provide an updated estimate of the effect of such therapy on the risk of hypoglycemia and death.

From the Departments of Medicine (Griesdale, Henderson, Chittock) and Anesthesiology, Pharmacology and Therapeutics (Griesdale), University of British Columbia; the Program of Critical Care Medicine (Griesdale, Henderson, Chittock) and the Department of Anesthesia (Griesdale), Vancouver General Hospital, Vancouver, BC; the Department of Nutrition (de Souza, van Dam), Harvard School of Public Health; the Channing Laboratory, Department of Medicine (van Dam), and the Divisions of Pulmonary, Critical Care and Sleep Medicine (Malhotra), Brigham and Women's Hospital and Harvard Medical School; the Department of Anesthesia, Critical Care and Pain Medicine, Beth Israel Deaconess Medical Center and Harvard Medical School (Talmor), Boston, USA; the Department of Medicine (Heyland), Queen's University; the Clinical Evaluation Research Unit (Dhaliwal), Kingston General Hospital, Kingston, Ont; the Departments of Medicine and of Clinical Epidemiology and Biostatistics (Cook), McMaster University, Hamilton, Ont.; and the Intensive Therapy Unit (Finfer), Royal North Shore Hospital, and the George Institute for International Health and the Faculty of Medicine (Finfer), University of Sydney, Sydney, Australia 


\section{Methods}

\section{Search strategy}

We systematically searched MEDLINE (1966-March 2008), EMBASE (1977-March 2008) and the Cochrane Central Register of Controlled Trials (CENTRAL) (1948-March 2008) for randomized trials examining the effect of intensive insulin therapy on mortality among critically ill patients. In addition, we conducted a manual search of abstracts from selected conferences held from 2000 to 2008, including conferences of the Society of Critical Care Medicine, the European Society of Intensive Care Medicine, the American Thoracic Society and the American College of Chest Physicians. We also searched by hand the bibliographies of all relevant trials. We obtained a confidential prepublication copy of the NICE-SUGAR report from the study's management committee. We included the NICE-SUGAR data subject to publication of the primary report and with the agreement of the journal publishing the trial.

For the bibliographic review, we constructed search filters for each of the concepts of critical care, intensive insulin therapy and clinical trials using a combination of exploded Medical Subject Heading (MeSH) terms and text words, all combined with the Boolean OR operator. The critical care filter contained the following MeSH terms: "critical care," "intensive care," "intensive care units," "cardiac care facilities," "critical illness," "postoperative care" with text words "intensive care," "ICU," "critical care," "CCU," "coronary care," "recovery room," "PAR," "critical illness," "burn unit," "critically ill" or "cardiac care." The intensive insulin filter contained the MeSH terms "insulin," "blood glucose," "hypoglycemic agents" with text words "intensive insulin," "glycemic control," "blood glucose" or "insulin." The clinical trials filter included the MeSH terms "clinical trials [publication type]," "clinical trials as topic," "placebos" with text words "trial*," "random*" or "placebo." We then combined all 3 filters using the Boolean operator AND. We used a similar search strategy to identify relevant articles in the EMBASE and CENTRAL databases (Appendix 1, available at www.cmaj.ca/cgi/content/full/cmaj.090206/DC1).

\section{Selection criteria}

In duplicate and independently, 2 of us (D.G. and R.D.) screened all of the articles and abstracts. Articles were selected if they met the following inclusion criteria: the study was a randomized controlled trial; the study participants were adults; a critical care setting was used; the intensive insulin therapy was defined by a target blood glucose concentration of $8.3 \mathrm{mmol} / \mathrm{L}$ or less; and the study documented mortality. We excluded trials that had not been published either in full or as abstracts in indexed journals.

\section{Data abstraction and methodologic quality}

Independently and in duplicate, the same 2 authors (D.G. and R.D.) abstracted data. They also assessed the methodologic quality of the trials using the Jadad score ${ }^{19}$ (Appendix 2, available at www.cmaj.ca/cgi/content/full/cmaj.090206/DC1). Disagreement was resolved by group discussion and arbitration by a third author (D.T.) if necessary. We abstracted year of publication, sample size, population (medical, surgical or mixed
ICU), patient age, reported illness severity score, initiation and maintenance criteria for insulin infusion in both the treatment and control arms, mean glucose concentration achieved in the treatment and control arms, length of ICU stay, and mortality. Hypoglycemic events were defined by a blood glucose level of $\leq 2.2 \mathrm{mmol} / \mathrm{L}$. For trials published in a language other than English, the translator abstracted the data in duplicate. We contacted investigators for missing data as necessary.

\section{Statistical analysis}

We used the risk ratio (RR) as the summary measure of association. We obtained the RR by pooling trial-specific cumulative incidence ratios from each arm of the included trials. If event rates were zero, we added a 0.5 continuity correction to all 4 cells. We generated a pooled-effect estimate and 95\% confidence intervals $(\mathrm{CI})$ using the DerSimonian and Laird randomeffects model ${ }^{20}$ which yields a more conservative pooled estimate than a fixed-effects model if true between-study heterogeneity exists. We estimated the degree of heterogeneity among trial results using Cochran's $\mathrm{Q}$ statistic (with a $p$ value less than 0.10 considered significant) and the $I^{2}$ statistic. ${ }^{21}$ The $I^{2}$ statistic indicates the percentage of variation in the study results that is because of between-study heterogeneity rather than sampling error. We identified potential sources of heterogeneity a priori as type of ICU (medical, surgical or mixed) and glycemic target in the intervention arm $(\leq 6.1 \mathrm{mmol} / \mathrm{L} \mathrm{v} . \leq 8.3 \mathrm{mmol} / \mathrm{L})$. We evaluated whether the trial results differed according to these criteria using random-effects meta-regression.

We selected 90-day mortality as our primary outcome measure. If this was not published in the primary report, we attempted to obtain these data from the trial authors. If this outcome was not recorded, we preferentially used the outcomes in the following order: hospital mortality, 28-day mortality and ICU mortality. The secondary outcome measure was hypoglycemic events (defined by a blood glucose level of $\leq 2.2 \mathrm{mmol} / \mathrm{L}$ ).

We evaluated the presence of publication bias using Begg's and Egger's tests ( $p$ value $<0.05$ considered significant) and by means of visual inspection of the funnel plot.

\section{Results}

\section{Literature search}

Through the electronic database search, we identified 2225 citations: 1079 from EMBASE, 785 from MEDLINE and 355 from the CENTRAL database (Figure 1). Of the 1474 unique citations, we excluded 1420 after screening the titles and abstracts. This left 54 articles for full-text review. The manual search of abstracts from conferences and of bibliographies yielded 8 additional trials that met our inclusion criteria. Overall, 28 articles were excluded (Figure 1). We included 26 trials $^{8-13,18,22-40}$ in the meta-analysis.

\section{Study characteristics}

Of the 26 included trials, 3 were published abstracts (Appendix 3, available at www.cmaj.ca/cgi/content/full/cmaj.090206/DC1). A total of 13567 patients participated; 7 trials included more than 500 patients (range 10-6104). The intervention glycemic 
target was $\leq 6.1 \mathrm{mmol} / \mathrm{L}$ in 16 trials, ${ }^{8-13,18,25,30,32,33,35,36,38-40}$ and 9 trials used a more liberal target of $\leq 8.3 \mathrm{mmol} / \mathrm{L} .^{22-24,26-28,31,34,37}$ One trial randomly assigned patients to 1 of 3 levels of glycemic control: $4.4-6.1 \mathrm{mmol} / \mathrm{L}, 6.7-8.3 \mathrm{mmol} / \mathrm{L}$ or $10.0-11.1 \mathrm{mmol} / \mathrm{L} .{ }^{29}$ Given our selection criteria of a target glucose level of $8.3 \mathrm{mmol} / \mathrm{L}$ or less, we combined data from the 2 intervention arms for our primary mortality analysis. Six trials were conducted in medical ICUs, 5 in surgical ICUs and 15 in mixed ICUs.

We used results from intention-to-treat analyses in our meta-analysis. However, 2 trials did not conduct this analysis because they excluded patients after randomization who did not survive at least 3 days. ${ }^{27,32}$ For 1 of these trials, ${ }^{32}$ we obtained the risk of both mortality and hypoglycemic events from the authors for the 18 patients excluded after randomization, which allowed us to include the intention-to-treat results for that trial.

\section{Mortality}

Data used in the primary analysis to determine the risk of death associated with intensive insulin therapy are listed in Appendix 4 (available at www.cmaj.ca/cgi/content/full/cmaj $.090206 / \mathrm{DC} 1)$. The pooled RR across all studies was 0.93

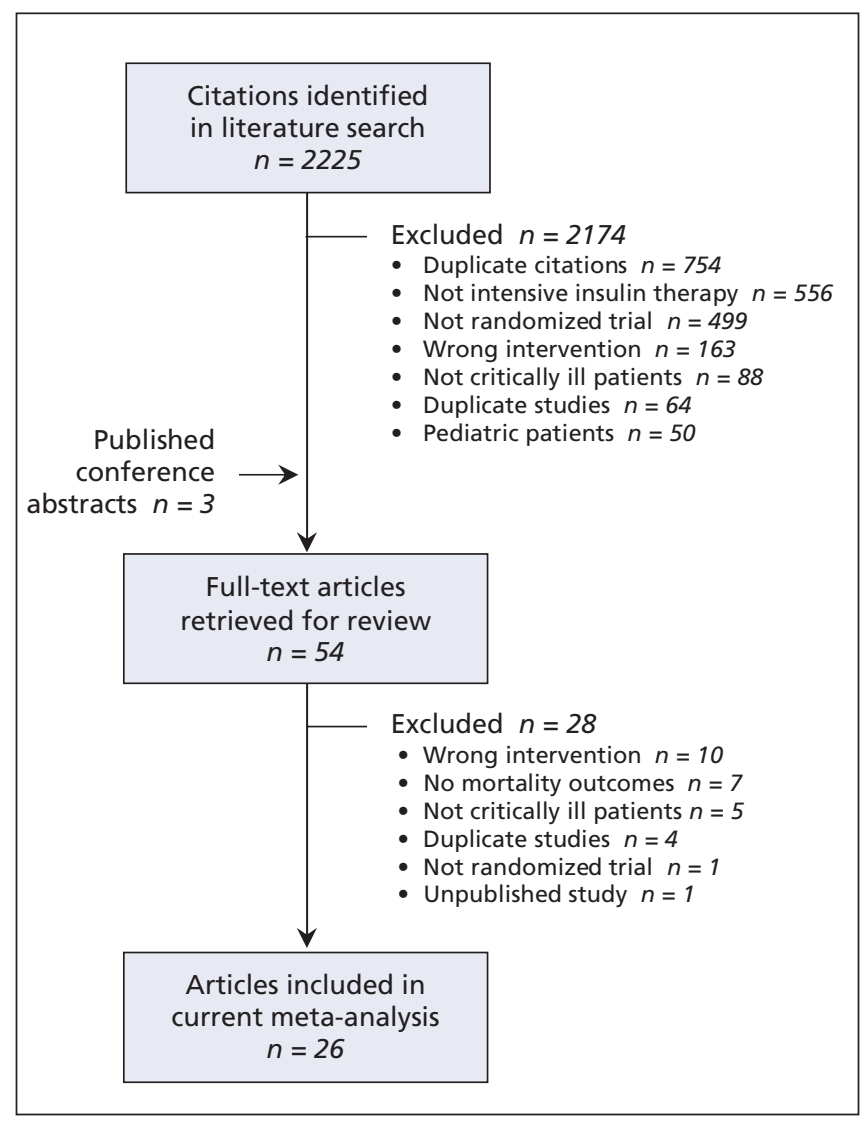

Figure 1: Section of studies for inclusion in the meta-analysis of the effect of intensive insulin therapy in critically ill patients. A total of 26 reports ( 23 published articles and 3 abstracts) were included in the final meta-analysis. Conferences included the Society of Critical Care Medicine, European Society of Intensive Care Medicine, American Thoracic Society and the American College of Chest Physicians.
(95\% CI 0.83-1.04) (Figure 2). There was significant heterogeneity between studies in our primary analysis $(\mathrm{Q}$ statistic $=$ $46.7, p=0.005)$, with a corresponding $I^{2}$ statistic of $46 \%$ (95\% CI 15\%-66\%). We examined the data for effect modification by type of ICU and target for intensive insulin therapy. In the meta-regression analysis, we found that patients in a surgical ICU benefitted from intensive insulin therapy compared with those in the control group $(p=0.02)$. The resultant pooled estimate RR by type of ICU were as follows: surgical ICU: RR 0.63 (95\% CI 0.44-0.91); medical ICU: RR 1.00 (95\% CI 0.78-1.28); and mixed ICU: RR 0.99 (95\% CI 0.86-1.12). Although only 5 trials enrolled patients in exclusively surgical ICUs, there was no statistical heterogeneity (Q statistic $=2.8, p=0.60)$, with a corresponding $I^{2}$ statistic of $0 \%(95 \%$ CI $0 \%-79 \%)$.

The intensity of insulin therapy (target glucose $\leq 6.1 \mathrm{mmol} / \mathrm{L}$ v. $\leq 8.3 \mathrm{mmol} / \mathrm{L}$ ) did not explain the heterogeneity of the trial results in the meta-regression $(p=0.81)$. For the trial that had 3 levels of glycemic control, ${ }^{29}$ we found no change in the overall pooled estimate when we considered a target glucose concentration of $\leq 6.1 \mathrm{mmol} / \mathrm{L}$ rather than $\leq 8.3 \mathrm{mmol} / \mathrm{L}(\mathrm{RR} 0.94,95 \%$ CI $0.85-1.05, p=0.29)$; the same was true in the meta-regression analysis examining the intensity of insulin therapy $(p=0.94)$.

\section{Hypoglycemic events}

Fourteen trials provided sufficient data on hypoglycemic events (Figure 3)..$^{8-13,18,22,25,31-33,35,36}$ The pooled RR was 6.0 (95\% CI 4.5-8.0), with some evidence of heterogeneity between studies $(\mathrm{Q}$ statistic $=20.7, p=0.08)$, with a corresponding $I^{2}$ statistic of $37 \%$ (95\% CI 0\%-67\%). We were unable to examine the data for effect modification by intensity of insulin therapy because only 1 trial that reported severe hypoglycemia used a target blood glucose level of $8.3 \mathrm{mmol} / \mathrm{L}$ or less. ${ }^{31}$ The risk of hypoglycemic events did not differ by type of ICU (data not shown).

\section{Publication bias}

We found no evidence of publication bias, either by funnel plot (data not shown) or by Begg's $(p=0.97)$ or Egger's $(p=0.06)$ test.

\section{Interpretation}

In our updated meta-analysis of randomized trials of intensive insulin therapy in critically ill patients, we found that such therapy had no effect on the overall risk of death. By including data from the largest trial of intensive insulin therapy, which was recently published, ${ }^{18}$ we provide the most current and precise estimate of the effect of intensive insulin therapy on mortality and severe hypoglycemia in the ICU setting. We found significant heterogeneity between studies, which was driven primarily by the 2 trials involving surgical patient populations. ${ }^{8,29}$ In keeping with this observation, our metaregression analysis suggested that intensive insulin therapy may benefit patients in surgical ICUs. Finally, there was a 6-fold increased risk of severe hypoglycemia among patients given intensive insulin therapy compared with the control 
treatment. The risk of hypoglycemic events did not differ by type of ICU, or by intensity of insulin therapy.

Our meta-analysis showed a similar overall pooled estimate of effect on mortality, and similar confidence intervals, as the meta-analysis by Wiener and colleagues. ${ }^{14}$ One important difference between these 2 reviews is our finding that the effect of intensive insulin therapy differed by ICU setting, with a benefit demonstrated among surgical patients. Weiner and colleagues did not find this. These discordant results may be explained by the inclusion of different trials. We excluded 3 unpublished trials that had been included by Wiener and colleagues. Although we found no evidence of publication

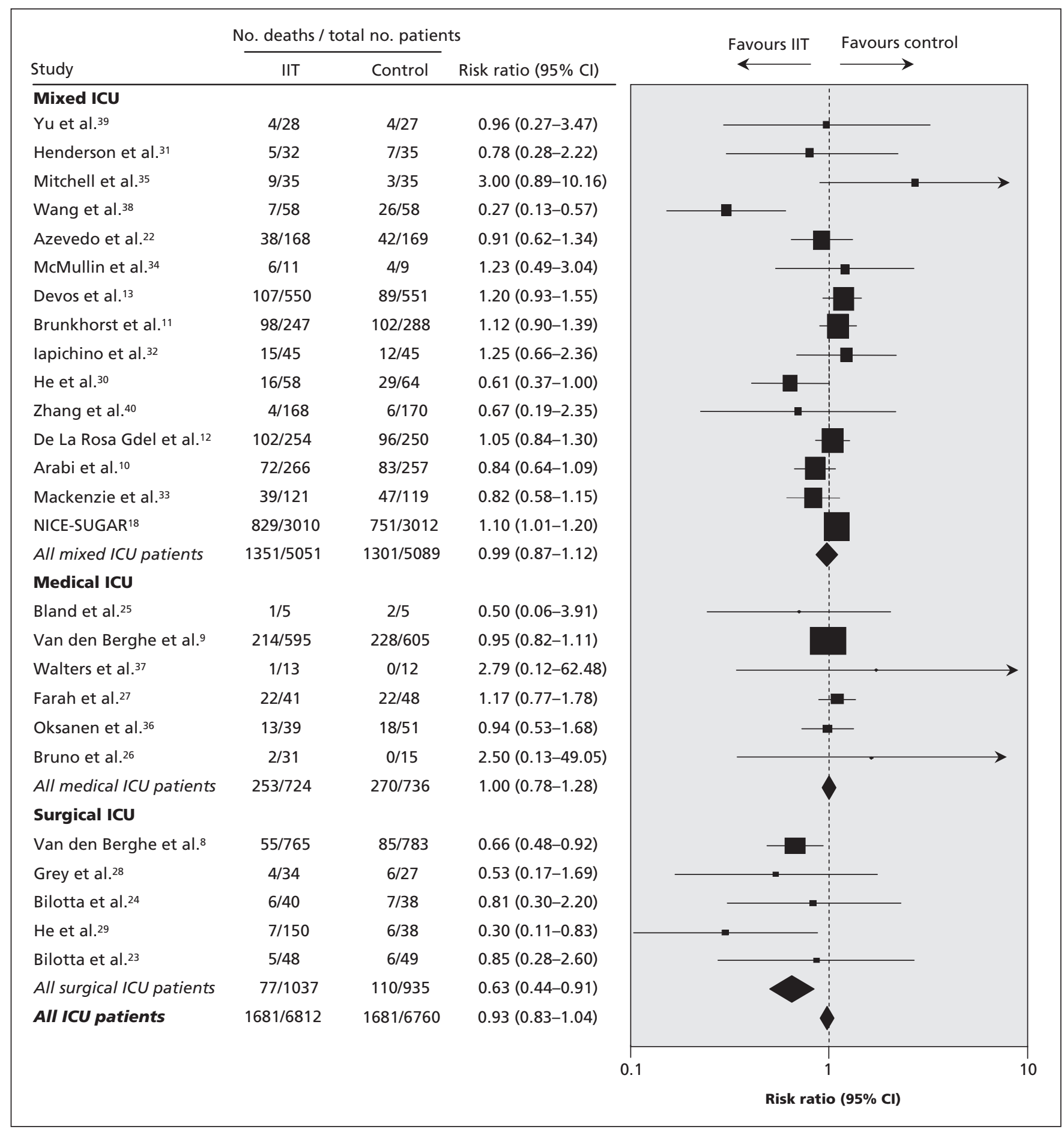

Figure 2: Risk ratios of mortality in clinical trials comparing intensive insulin therapy (IIT) to conventional glycemic control stratified by type of ICU. Tests for heterogeneity: mixed ICU: Q statistic $=29.54(p<0.01), R=52.6 \%$; medical ICU: Q statistic $=2.05(p=0.84), R=$ $0.0 \%$; surgical ICU: Q statistic $=2.78(p=0.60), I^{2}$ statistic $0.0 \%$; all ICU patients: Q statistic $=46.67(p<0.01), R=46.4 \%$. Note: $\mathrm{Cl}=$ confidence interval. 
bias in our analysis, the tests we used may be unreliable in the presence of significant heterogeneity. ${ }^{41}$ However, since neither peer reviewers nor we have been able to assess the methodologic quality of the unpublished trials, we decided to include only trials published either in full or as abstracts in indexed journals. ${ }^{42}$ In addition, following translation, data abstraction and quality assessment, we included 1 trial that had been excluded by Wiener and colleagues, ${ }^{29}$ this trial was conducted in a surgical ICU and strongly favoured intensive insulin therapy. Although the NICE-SUGAR study included 2233 surgical patients and mortality was significantly increased in this subgroup, this study was conducted in mixed ICUs and was analyzed accordingly in our meta-analysis. The increased mortality in surgical patients enrolled in the NICESUGAR trial, the majority of whom were admitted to the ICU following emergency surgery, suggests that the benefit of intensive insulin therapy in patients treated in surgical ICUs requires confirmation.

Our findings of a significantly increased risk of hypoglycemia with intensive insulin therapy are in keeping with those reported by Wiener and colleagues. ${ }^{14}$ However, the analysis of differences in the risk of hypoglycemia between subgroups is limited by the low number of included studies.

Finally, our findings do not support the guidelines of organizations such as the American Diabetes Association, the American Association of Clinical Endocrinologists and other organizations, including the Surviving Sepsis Campaign, who recommend intensive insulin therapy for all critically ill patients. ${ }^{15-17,43}$ Our meta-analysis incorporates the results of the largest trial to date. We are not aware of any ongoing trial of sufficient size to affect these results; thus, we suggest that policy-makers reconsider recommendations promoting the use of intensive insulin therapy in all critically ill patients. However, ours was a pooled analysis of trials conducted in different populations with differing severity of illnesses and event rates; therefore, we cannot exclude the possibility that some patients may benefit from intensive insulin therapy. A meta-analysis of individual patient data and additional randomized trials may help to delineate which patients may benefit from intensive insulin therapy and be at lower risk of hypoglycemic events.

This review highlights a number of important questions that remain to be answered; most notable, why the beneficial treatment effect observed in Van den Berghe's first trial ${ }^{8}$ has not been observed in subsequent multicentre trials involving adults. First, it may be that patients admitted to surgical ICUs after elective surgery benefit from intensive insulin therapy and that subsequent trials have not adequately examined this subgroup. Although this is suggested by our meta-regression showing a beneficial effect in patients admitted to surgical ICUs, subgroup analyses must be interpreted with caution, particularly in the setting of low event rates. ${ }^{44,45}$ In the surgical ICU subgroup, there were only 77 deaths in the intensive insulin therapy group and 110 in the usual care group.

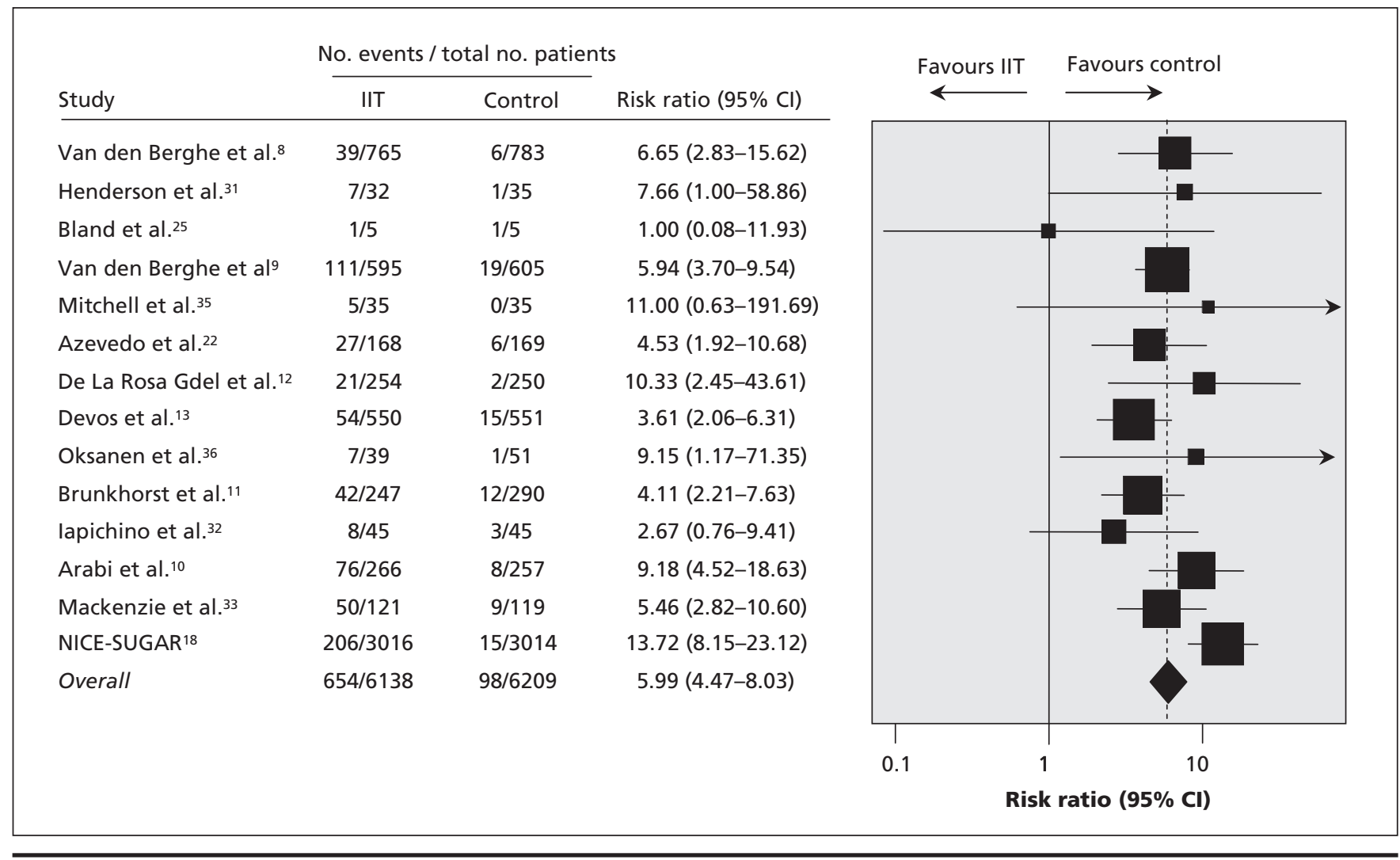

Figure 3: Risk ratios of hypoglycemic events in clinical trials comparing intensive insulin therapy (IIT) to conventional glycemic control. The dashed vertical line represents the pooled estimate. There was significant heterogeneity between trials $(Q$ statistic $=20.71, p=$ $0.08, R=37.0 \%)$. Note: $\mathrm{Cl}=$ confidence interval. 
A second possibility is that, because intensive insulin therapy is a complex treatment and the results may be dependent on the implementation of the intervention and the accuracy of blood glucose measurement, ${ }^{46}$ these factors may have differed between Van den Berghe's first trial and subsequent trials. There is some evidence for this in the wide range of hypoglycemic events in the intervention arms between trials (from $5.1 \%-28.6 \%$ ). A further explanation is the considerable variability in what constitutes "usual care." In the trial by Van den Berghe and colleagues, the control group targeted a blood glucose level of 10.0-11.1 mmol/L. In contrast, some of the trials included in our analysis used a lower glucose target in the control group. For example, in the control arms of the trials by the NICE-SUGAR group and by Oksanen and colleagues ${ }^{36}$ the targeted blood glucose level was less than $10.0 \mathrm{mmol} / \mathrm{L}$ and $6.0-8.0 \mathrm{mmol} / \mathrm{L}$, respectively. In settings where usual care is to target a blood glucose level of less than $10.0 \mathrm{mmol} / \mathrm{L}$, intensive insulin therapy may offer no benefit.

Another possible explanation for the discordant results between trials is that the degree with which blood glucose levels fluctuates in an individual patient may be as important as the average blood glucose concentration achieved. ${ }^{47} \mathrm{It}$ is possible for 2 trials to report having achieved similar mean blood glucose concentration while obscuring the fact that blood glucose variability was markedly different between the 2 trials. Finally, the impact of feeding regimens on the effect of intensive insulin therapy requires urgent clarification. The patients in the trial by Van den Berghe and colleagues ${ }^{8}$ were fed largely by the parenteral route and received large doses of intravenous glucose. ${ }^{9}$ In contrast, patients in other studies, such as the NICE-SUGAR study, received predominantly enteral nutrition. ${ }^{18}$ We hypothesize that the treatment effect of intensive insulin therapy may be dependent on the means of controlling blood glucose, the accuracy of blood glucose monitoring, the degree of within-patient variation in blood glucose and the feeding regimen used. These hypotheses can be further explored through meta-analysis of individual patient data ${ }^{48}$ and by rigorous, adequately powered and carefully conducted randomized controlled trials.

\section{Conclusion}

In summary, the results of our updated meta-analysis do not support widespread adoption of intensive insulin therapy in critically ill patients. We cannot exclude the possibility that some patients may benefit from intensive insulin therapy, although the characteristics of such patients remain to be clearly defined; as does the effect of different blood glucose algorithms, the method of measuring blood glucose and the influence of nutritional strategies. An individual patient data meta-analysis would help to address these questions.

\section{This article was peer reviewed and fast-tracked.}

Competing interests: Atul Malhotra is a consultant for Pfizer, which previously sold a form of inhaled insulin that is now discontinued. Simon Finfer received travel assistance to attend and present at a Cardinal Health meeting in 2007.

None declared for Donald Griesdale, Russell de Souza, Rob van Dam, Daren Heyland, Deborah Cook, Rupinder Dhaliwal, William Henderson, Dean Chittock and Daniel Talmor.
Contributors: Donald Griesdale had full access to all of the data and takes responsibility for the integrity of the data and the accuracy of the data analysis. He was involved in the study concept, design, acquisition of data, analysis and interpretation of data, drafting the manuscript, critical review of the manuscript and the statistical analysis. Russell de Souza was involved in the acquisition of data, analysis and interpretation of data, drafting of the manuscript, critical review of the manuscript and the statistical analysis. Daniel Talmor and Atul Malhotra were involved in the study concept, design, analysis and interpretation of data, and critical review of the manuscript. Rob van Dam was involved in the analysis and interpretation of data and critical review of the manuscript. Simon Finfer, Deborah Cook, Daren Heyland, William Henderson and Dean Chittock were involved in the interpretation of data and critical review of the manuscript. Rupinder Dhaliwal was involved in the data abstraction and critical review of the manuscript. All of the authors approved the final version submitted for publication.

Acknowledgements: We thank Dr. Anton Chau, Dr. Juan Ronco and Mrs. Nancy Liu for translation of non-English publications. We also thank all of the authors of publications included in this study for contributing information as required.

Funding: No external funding was received for this research.

\section{REFERENCES}

1. Sung J, Bochicchio GV, Joshi M, et al. Admission hyperglycemia is predictive of outcome in critically ill trauma patients. J Trauma 2005;59:80-3.

2. Whitcomb BW, Pradhan EK, Pittas AG, et al. Impact of admission hyperglycemia on hospital mortality in various intensive care unit populations. Crit Care Med 2005; 33:2772-7.

3. Malmberg K, Norhammar A, Wedel H, et al. Glycometabolic state at admission: Important risk marker of mortality in conventionally treated patients with diabetes mellitus and acute myocardial infarction: long-term results from the diabetes and insulin-glucose infusion in acute myocardial infarction (DIGAMI) study. Circulation 1999;99:2626-32.

4. McCowen KC, Malhotra A, Bistrian BR. Stress-induced hyperglycemia. Crit Care Clin 2001; 17:107-24

5. Capes SE, Hunt D, Malmberg K, et al. Stress hyperglycemia and prognosis of stroke in nondiabetic and diabetic patients: A systematic overview. Stroke 2001; 32:2426-32

6. Gale SC, Sicoutris C, Reilly PM, et al. Poor glycemic control is associated with increased mortality in critically ill trauma patients. Am Surg 2007;73:454-60.

7. Krinsley JS. Association between hyperglycemia and increased hospital mortality in a heterogeneous population of critically ill patients. Mayo Clin Proc 2003;78: 1471-8.

8. Van den Berghe G, Wouters P, Weekers F, et al. Intensive insulin therapy in critically ill patients. N Engl J Med 2001;345:1359-67.

9. Van den Berghe G, Wilmer A, Hermans G, et al. Intensive insulin therapy in the medical ICU. $N$ Engl J Med 2006;354:449-61.

10. Arabi YM, Dabbagh OC, Tamim HM, et al. Intensive versus conventional insulin therapy: A randomized controlled trial in medical and surgical critically ill patients. Crit Care Med 2008;36:3190-7.

11. Brunkhorst FM, Engel C, Bloos F, et al. Intensive insulin therapy and pentastarch resuscitation in severe sepsis. N Engl J Med 2008;358:125-39.

12. De La Rosa Gdel D., Donado JH, Restrepo AH, et al. Strict glycaemic control in patients hospitalised in a mixed medical and surgical intensive care unit: a randomised clinical trial. Crit Care 2008;12:R120.

13. Devos P, Preiser J, Mélot C. Impact of tight glucose control by intensive insulin therapy on ICU mortality and the rate of hypoglycaemia: final results of the glucontrol study [abstract]. Intensive Care Med 2007;33:S189.

14. Wiener RS, Wiener DC, Larson RJ. Benefits and risks of tight glucose control in critically ill adults: A meta-analysis. JAMA 2008;300:933-44.

15. American Diabetes Association. Standards of medical care in diabetes - 2008. Diabetes Care 2008;31(Suppl 1):S12-54.

16. AACE Diabetes Mellitus Clinical Practice Guidelines Task Force. American Association of Clinical Endocrinologists medical guidelines for clinical practice for the management of diabetes mellitus. Endocr Pract 2007;13(Suppl 1):1-68.

17. Institute for Healthcare Improvement. Implement effective glucose control: establish a glycemic control policy in your ICU. Cambridge (MA): The Institute; Available: www.ihi.org/IHI/Topics/CriticalCare/IntensiveCare/Changes/IndividualChanges /EstablishaGlycemicControlPolicyin YourICU.htm (accessed 2009 Jan. 27).

18. NICE-SUGAR Study Investigators. Intensive versus conventional glucose control in critically ill patients. $N$ Engl J Med 2009;360:1283-97.

19. Jadad AR, Moore RA, Carroll D, et al. Assessing the quality of reports of randomized clinical trials: Is blinding necessary? Control Clin Trials 1996;17:1-12.

20. DerSimonian R, Laird N. Meta-analysis in clinical trials. Control Clin Trials 1986; 7:177-88.

21. Higgins JP, Thompson SG, Deeks JJ, et al. Measuring inconsistency in metaanalyses. BMJ 2003;327:557-60.

22. Azevedo JR, de Araujo LO, Azevedo RP, et al. Intensive insulin therapy versus 
glycemic control in critically ill patients: a prospective controlled trial [abstract] Crit Care 2007;11(Suppl 3):P82.

23. Bilotta F, Caramia R, Cernak I, et al. Intensive insulin therapy after severe traumatic brain injury: A randomized clinical trial. Neurocrit Care 2008;9:159-66.

24. Bilotta F, Spinelli A, Giovannini F, et al. The effect of intensive insulin therapy on infection rate, vasospasm, neurologic outcome, and mortality in neurointensive care unit after intracranial aneurysm clipping in patients with acute subarachnoid hemorrhage: A randomized prospective pilot trial. J Neurosurg Anesthesiol 2007; 19:156-60.

25. Bland DK, Fankhanel Y, Langford E, et al. Intensive versus modified conventional control of blood glucose level in medical intensive care patients: a pilot study. Am J Crit Care 2005;14:370-6.

26. Bruno A, Kent TA, Coull BM, et al. Treatment of hyperglycemia in ischemic stroke (THIS): a randomized pilot trial. Stroke 2008;39:384-9.

27. Farah R, Samokhvalov A, Zviebel F, et al. Insulin therapy of hyperglycemia in in tensive care. Isr Med Assoc J 2007;9:140-2.

28. Grey NJ, Perdrizet GA. Reduction of nosocomial infections in the surgical intensive-care unit by strict glycemic control. Endocr Pract 2004;10:46-52.

29. He W, Zhang TY, Zhou H, et al. Impact of intensive insulin therapy on surgical critically ill patients [Chinese]. Zhonghua Wai Ke Za Zhi 2007;45:1052-4.

30. He ZY, Li N, Xing J, et al. Effect of intensive insulin therapy on short-term outcome in critically ill patients. Chinese J Clin Nutr 2008;16:220-2.

31. Henderson WR, Dhingra VK, Chittock DR, et al., in association with the Canadian Critical Care Trials Group. Survival using glucose algorithm regulation (SUGAR) trial — pilot data [abstract]. New York (NY): American Thoracic Society; 2005. A37.

32. Iapichino G, Albicini M, Umbrello M, et al. Tight glycemic control does not affect asymmetric-dimethylarginine in septic patients. Intensive Care Med 2008;34:1843-50.

33. Mackenzie IM, Ercole A, Ingle S, et al. Glycaemic control and outcome in genera intensive care: The east anglian GLYCOGENIC study. Br J Intensive Care 2008 18:121-6

34. McMullin J, Brozek J, McDonald E, et al. Lowering of glucose in critical care: a randomized pilot trial. J Crit Care 2007;22:112-8.

35. Mitchell I, Knight E, Gissane J, et al. A phase II randomised controlled trial of in tensive insulin therapy in general intensive care patients. Crit Care Resusc 2006;8: 289-93.

36. Oksanen T, Skrifvars MB, Varpula T, et al. Strict versus moderate glucose control af ter resuscitation from ventricular fibrillation. Intensive Care Med 2007:33:2093-100.

37. Walters MR, Weir CJ, Lees KR. A randomised, controlled pilot study to investi- gate the potential benefit of intervention with insulin in hyperglycaemic acute ischaemic stroke patients. Cerebrovasc Dis 2006;22:116-22.

38. Wang LC, Lei S, Wu YC, et al. Intensive insulin therapy in critically ill patients [Chinese]. Zhongguo Wei Zhong Bing Ji Jiu Yi Xue 2006;18:748-50.

39. Yu WK, Li WQ, Wang XD, et al. Influence and mechanism of a tight control of blood glucose by intensive insulin therapy on human sepsis [Chinese]. Zhonghua Wai Ke Za Zhi 2005;43:29-32.

40. Zhang R-, He W, Li T, et al. Evaluation of optimal goal of glucose control in critically ill patients. Chinese J Clin Nutr 2008;16:204-8

41. Ioannidis JP, Trikalinos TA. The appropriateness of asymmetry tests for publication bias in meta-analyses: A large survey. CMAJ 2007;176:1091-6.

42. Egger M, Smith GD, Altman DG, editors. Systematic reviews in health care. Metaanalysis in context. 2nd ed. London (UK): BMJ Publishing Group; 2001.

43. Dellinger RP, Levy MM, Carlet JM, et al. Surviving sepsis campaign: International guidelines for management of severe sepsis and septic shock: 2008. Crit Care Med 2008;36:296-327.

44. Bradburn MJ, Deeks JJ, Berlin JA, et al. Much ado about nothing: a comparison of the performance of meta-analytical methods with rare events. Stat Med 2007;26: 53-77.

45. Devereaux PJ, Goldman L, Cook DJ, et al. Perioperative cardiac events in patient undergoing noncardiac surgery: a review of the magnitude of the problem, the pathophysiology of the events and methods to estimate and communicate risk. CMAJ 2005; 173:627-34.

46. Scott MG, Bruns DE, Boyd JC, et al. Tight glucose control in the intensive care unit: Are glucose meters up to the task? Clin Chem 2009;55:18-20.

47. Egi M, Bellomo R, Stachowski E, et al. Variability of blood glucose concentration and short-term mortality in critically ill patients. Anesthesiology 2006;105:244-52.

48. Reade MC, Delaney A, Bailey MJ, et al. Bench-to-bedside review: avoiding pitfalls in critical care meta-analysis-funnel plots, risk estimates, types of heterogeneity, baseline risk and the ecologic fallacy. Crit Care 2008;12:220.

Correspondence to: Dr. Donald E.G. Griesdale, Critical Care Medicine, Vancouver General Hospital, Rm. 2438, Jim Pattison

Pavilion, 2nd Floor, 855 West 12th Ave., Vancouver BC V5Z 1M9; fax 604 875-5957; dgriesdale@ post.harvard.edu

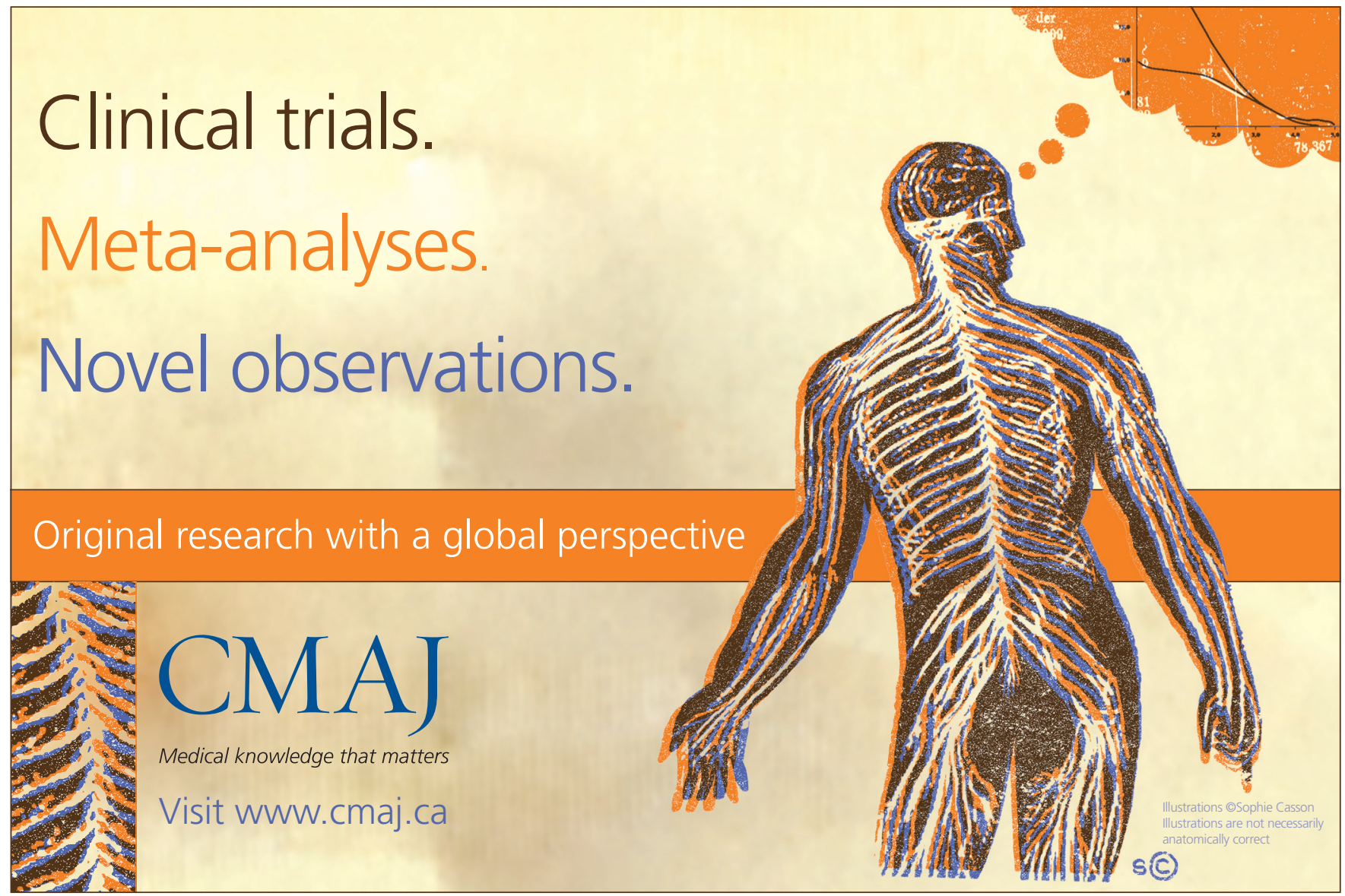

